\title{
La integración andina en el marco constitucional de los países miembros de la Comunidad Andina (CAN)*
}

\section{Andean integration in the constitutional framework of the member countries of the Andean Community (CAN)}

Fecha de recepción: 6 de abril de 2011 Fecha de evaluación: 20 de junio de 2011 Fecha de aprobación: 21 de junio de 2011

Carolina Blanco Alvarado*

\section{Resumen}

Mediante las presentes líneas se pretende una aproximación al marco constitucional de la integración andina. Para lo anterior, se contextualizará lo previsto sobre el particular, en la Constitución Colombiana, en concordancia con lo dispuesto en las demás cartas políticas de los países miembros de la Comunidad Andina (CAN).

En este sentido, se analizará la crisis que a la fecha evidencian las fuentes clásicas del derecho, las relaciones entre el derecho constitucional y el derecho andino de la integración y la perspectiva constitucional del proceso de integración andino en los Estados que conforman la Comunidad Andina (CAN).

Palabras clave: Integración andina, ordenamiento jurídico andino, derecho constitucional, Constitución Política

\footnotetext{
* Artículo de reflexión.

** Magíster en Derechos Fundamentales, Universidad Carlos III de Madrid - España. Especialista en Derecho Constitucional, Centro de Estudios Políticos y Constitucionales de Madrid - España. Especialista en Derecho Administrativo, Universidad del Rosario de Bogotá - Colombia. Correo electrónico: carolinablancoalvarado@hotmail.com
} 


\begin{abstract}
The objective of these lines is to make an approach to the constitutional framework of the Andean integration Context. To this end we will contextualize the particular provisions in the Colombian Constitution, in accordance with the provisions on the particular policies in the other letters of the member countries of the Andean Community (CAN).

For the above, the crisis which to date is showing the classic sources of law will be analyzed as well as the relationship between constitutional law and the Andean integration Law and the constitutional perspective of the Andean integration process in the States of the Andean Community (CAN).
\end{abstract}

Keywords: Andean integration, the Andean legal system, constitutional law, Constitution

\title{
INTRODUCCIÓN
}

Con las presentes páginas se pretende contextualizar el impacto constitucional del ordenamiento jurídico andino en las cartas políticas de los países miembros de la Comunidad Andina. Esto es, intentar lograr una aproximación entre el derecho constitucional de los referenciados países con el derecho andino de la integración.

Todo lo anterior con la finalidad de concluir que es necesaria la implementación de la normatividad constitucional andina en el marco de lo que debe ser el derecho andino de la integración.

Para el efecto se ha verificado el contenido de las constituciones de Bolivia, Colombia, Ecuador y Perú, en lo referente al proceso andino de integración, y en concordancia con doctrina propia de la Unión Europea y de los países miembros de la Comunidad Andina (CAN).

\section{UN NUEVO PARADIGMA ESTÁ SURGIENDO}

Uno de los desafíos a los que se enfrenta el Estado de derecho de los países andinos es el que deriva de la pérdida de soberanía de los mismos, por el desplazamiento de las fuentes del derecho fuera de sus confines y el debilitamiento del papel garantista de las constituciones nacionales. Una propuesta de solución frente a la circunstancia mencionada es la promoción de la integración jurídica e institucional, e intentar el desarrollo de un constitucionalismo sin Estado, esto es, a la altura de los nuevos espacios, no estatales, sino supraestatales (Ferrajoli, 2003: 23-27).

En concordancia con lo dispuesto anteriormente, en la actualidad se conectan los fenómenos de la fragmentación jurídica y la desformalización, con progresiva pérdida de relevancia de los caracteres propios de las "fuentes formales" del derecho, así como la deslegalización, con la correspondiente erosión de la idea de ordenamiento jurídico en cuanto estructura normativa global y unitaria. Esta situación refleja fielmente la situación, no sólo del derecho estatal, sino también, y es lo que nos interesa ahora, del ordenamiento jurídico andino (De Cabo, 2000).

Siempre se ha considerado como un dogma el monopolio de la creación del derecho por parte del Estado. Este principio fundamental se encuentra en quiebra desde el inicio mismo del proceso de integración andina. El derecho ya no es creado sólo por los Estados andinos, sino que además, y de modo cada vez más intenso y extenso, lo es por parte de entes supranacionales como la Comunidad Andina, y específicamente de los órganos e instituciones que la conforman. Este derecho, 
ajeno al Estado, se aplica directamente en los Estados miembros sin necesidad de acto alguno de recepción. Lo anterior, en principio, permitiría afirmar que altera todos los fundamentos clásicos del derecho constitucional en el ámbito de las fuentes del derecho, desafiando la autoridad normativa de este y de las constituciones de los países andinos (Chofre, 2007).

En definitiva, en el derecho andino de la integración u ordenamiento jurídico andino se produce pérdida en la capacidad reguladora de la "ley" y de la unidad y coherencia de las fuentes, así como de la convivencia y superposición de ordenamientos concurrentes. Tal situación, descrita con dichos rasgos genéricos, nos conduce a un derecho con una relación sui géneris con los ordenamientos jurídicos de los países que conforman la Comunidad Andina (CAN).

\section{DERECHO CONSTITUCIONAL Y DERECHO ANDINO DE LA INTEGRACIÓN}

La legalización de tratados internacionales que inician y desarrollan el proceso de integración andino requiere de norma constitucional. Para el efecto, el referenciado proceso se justifica en el sentido en que un Estado aislado, en un mundo globalizado, puede verse condenado al fracaso o estancamiento económico (Ravassa, 2005), especialmente cuando los niveles de competitividad y producción se incrementan constantemente.

La integración andina requiere como presupuesto el traslado de ciertas competencias del orden nacional a órganos de carácter supranacional. En este sentido, y para que el Estado pueda ceder parte de sus competencias, es necesario un soporte constitucional, pues esta facultad es ejercitable por un Estado siempre y cuando su cláusula general de competencia le permita que, dentro de su actuación soberana, se puedan delegar competencias a instituciones supranacionales, y convertir las com- petencias de los órganos estatales en funciones residuales y subsidiarias (Palomares, 2008).

Para el efecto, la principal connotación que levanta la participación del Estado en un mecanismo de integración, desde el punto de vista de la Carta Política, se denomina cuestión constitucional que puede resumirse en

\section{[...] el análisis de la compatibilidad de las normas de la constitución nacional con un sistema regional que establezca la limitación, delegación o transferencias de competencias de actuación (hasta ahora monopólicamente administradas por las autoridades públicas) a órganos exteriores del Estado, a los cuales se les confíe la facultad de emitir normas jurí- dicas obligatorias de integración a nacio- nales y Estados (Perotti, 2007: 18).}

Ahora bien, si de lo que se trata es de anteponer la primacía del derecho andino de la integración a la Constitución de los Estados miembros, hay que decir que ello, sencillamente, no resulta de recibo, en razón a que las constituciones andinas se aplican en los ámbitos que siguen siendo competencia del Estado miembro pero atribuidos a la integración andina; en este último evento, se aplica el derecho andino en toda su plenitud y el Estado no puede invocar la Constitución para impedir los efectos de la norma andina válida (Plata, 2009).

El proceso andino de integración plantea una serie de exigencias jurídicas que tienen repercusión en el ámbito constitucional interno de cada país. Estas exigencias son, en primer lugar, que los órganos comunitarios supranacionales que se establezcan pueden tomar decisiones obligatorias para los Estados miembros; en segundo lugar, que las decisiones de tales órganos sean adaptadas en ejercicio de las competencias que tradicionalmente corresponden a los órganos constitucionales de los Estados miembros individualmente considerados, por lo que para su establecimiento es indispensable que aquellos órganos transfieran 
poderes y competencias a los órganos supranacionales; en tercer lugar, que las decisiones de estos sean directa e inmediatamente aplicables a los Estados miembros, tanto a los órganos públicos como a los ciudadanos, y en cuarto lugar, que el derecho comunitario producido por los órganos supranacionales no solo tenga primacía en el derecho interno, sino que se escape del control de constitucionalidad, y esté sometido, en cambio, al control de conformidad con los tratados de integración por un tribunal de justicia supranacional (Brewer, 2003).

El proceso de integración andina ha llegado a un punto en el cual es necesario revisar sus fundamentos y mecanismos de actuación. Hasta ahora, la integración andina se ha realizado sobre la base de sucesivos tratados internacionales que atribuyen a las instituciones comunitarias poderes que se pueden ampliar en función de los objetivos y que permiten una evolución progresiva del proceso de integración, siempre que exista acuerdo entre los Estados miembros, olvidándose del impacto que la referenciada normatividad evidencia en el marco constitucional de los países miembros de la Comunidad Andina. Lo anterior en razón a que, una vez legalizados los tratados, protocolos y acuerdos que regulan la integración andina, es cuestionable el valor vinculante que tienen los mismos y la afectación de dichas normas sobre el ordenamiento jurídico interno de los países miembros (Palomares, 2008).

Sólo desde la existencia de un verdadero marco constitucional se hace posible una articulación coherente que solucione los conflictos entre el derecho constitucional y el derecho andino de la integración, lo cual, obviamente, permitiría un ajuste correcto de las relaciones entre los referenciados ordenamientos. Es por lo anterior que resulta procedente afirmar que sólo cuando se realice la integración constitucional andina será posible promover formas avanzadas de integración y de unificación legislativa (Balaguer, 1991).

\section{LA PREVALENCIA DEL ORDENAMIENTO JURÍDICO ANDINO EN EL DERECHO CONSTITUCIONAL COLOMBIANO}

Con la Carta Política de 1991 se consagró como principio fundamental la prevalencia de la norma constitucional sobre las normas del derecho internacional. Para el efecto, el artículo $4^{\circ}$ de dicha normatividad dispone que "la Constitución es norma de normas" y que "en todo caso de incompatibilidad de la Constitución y la ley u otra norma jurídica, se aplicarán las disposiciones constitucionales".

Al respecto, la Corte Constitucional colombiana, mediante Sentencia C-400 de 1998 y cuyo magistrado ponente fue Alejandro Martínez Caballero, por la cual se declaró la exequibilidad de la Convención de Viena sobre el derecho de los tratados entre Estados y organizaciones internacionales o entre organizaciones internacionales, reiteró el valor prevalente de la Constitución, indicando clara y expresamente dos excepciones al particular: 1) tratados que reconocen derechos humanos y prohíben su limitación en estados de excepción, los cuales se integran al bloque de constitucionalidad, y 2) tratados de límites fronterizos, esto último en aras de mantener la convivencia del Estado colombiano en paz y como quiera que dichos tratados regulan uno de los elementos del Estado.

En este orden de ideas, la jurisprudencia de la Corte Constitucional ha reiterado que en el derecho interno los tratados internacionales no prevalecen sobre la Constitución, salvo en lo referente a los dos aspectos mencionados anteriormente. Sin embargo, es pertinente anotar que existe en la actualidad una tercera excepción, atendiendo al contenido del artículo 93 de la Carta colombiana, pues por vía jurisprudencial la Corte abrió camino a la tesis según la cual el derecho emanado de los organismos supranacionales de integración andina prevalecen sobre el orden interno (Ramírez, 2008). Así pues, en sentencias C-231 de 1997 y C-227 de 
1999, m. p. Eduardo Cifuentes Muñoz, se consideró que el derecho comunitario, como consecuencia de su característica de normatividad supranacional, prevalece en el orden interno.

\section{ALGUNAS ANOTACIONES DE LA PERSPECTIVA CONSTITUCIONAL DE LA INTEGRACIÓN ANDINA}

1. Las constituciones de los países andinos son claras y expresas al establecer y promover el proceso de integración andino, lo cual se evidencia en el artículo 265 de la Carta Política boliviana, en los artículos 416 y 423 de la Constitución ecuatoriana, y desde el preámbulo y específicamente en los artículos 90, 150, 226 y 227 de la Carta Política colombiana.

Con relación a la Carta Política peruana de 1993, se puede constatar que el tema de la integración andina, a diferencia de los demás países miembros de la Comunidad Andina, no dedica toda una articulación sobre el particular, motivo por el cual resulta procedente afirmar que, de manera tangencial e indirecta, tal tema está previsto en el artículo 55 de la Constitución peruana, el cual prevé que "Ios tratados celebrados por el Estado y en vigor, forman parte del derecho nacional". Este enunciado simple asegura que el Acuerdo de Cartagena, y los protocolos que lo han modificado, son leyes vigentes en el Perú y por tanto de obligatorio cumplimiento. Sin embargo, la norma constitucional es insuficiente para el reconocimiento pleno del principio de supranacionalidad por parte de las autoridades peruanas, pues tal como está el texto constitucional, el ordenamiento jurídico andino queda por debajo de la Constitución y en el mismo rango de la ley, y en caso de conflicto entre las normas internas y las comunitarias, las autoridades podrán optar por aplicar las primeras sobre las segundas, lo cual generaría para el Perú responsabilidad internacional por incumplimiento de normas del ordenamiento jurídico andino (Tangarife, 2002). En consecuencia, al verificar la Carta
Política peruana se puede constatar que no hay aplicabilidad del principio de supranacionalidad, porque si hay conflicto entre la norma comunitaria y la interna prevalece la segunda, ya que el artículo 51 de la Constitución Política establece que esta prevalece sobre toda norma legal (Martínez, 2008).

2. Con respecto a la relación entre el derecho internacional y el derecho interno, los Estados andinos, como ocurre en casi todos los Estados modernos, han acogido en su texto constitucional la teoría dualista; lo cual significa que los referenciados ámbitos jurídicos se constituyen como dos perspectivas del derecho completamente separadas, y como consecuencia de ello, para que el derecho internacional tenga validez en el plano interno, normalmente "requiere del órgano legislativo, esto es, debe llevarse a cabo una transformación del derecho internacional en derecho nacional" (Caballero \& Anzola, 1995: 29).

Lo anterior es aplicable también a los tratados, acuerdos y protocolos que conforman el ordenamiento jurídico andino. Si bien este ordenamiento ostenta características diferentes a las del derecho internacional, el proceso de recepción al derecho interno de dicho ordenamiento implica la aplicación de la mencionada teoría dualista.

Al respecto, es pertinente anotar que la cultura internacionalista de nuestro tiempo ha llevado a producir variadas modalidades de acuerdos internacionales, lo que se traduce de manera gradual en una tendencia a disminuir las solemnidades propias de los tratados en punto a perfeccionamiento.

La rapidez en la evolución de la realidad internacional, y los correspondientes cambios que exige la diversa gama de intereses y problemas que comporta, en determinadas áreas, se viene reflejando en una flexibilidad de los trámites para la celebración de los tratados internacionales (Ramírez, 2008: 17).

Lo afirmado anteriormente debe tenerse en cuenta en el proceso de legalización de los tratados, 
acuerdos y protocolos que conforman el ordenamiento jurídico andino, e iniciar el debate de la procedencia o no de la intervención del legislativo y del papel de las cortes constitucionales o tribunales constitucionales en el trámite de perfeccionamiento de dichas normas.

3. Al verificar el contenido de las constituciones de los países andinos, se puede constatar que en las mismas no existe fundamento constitucional suficiente para admitir la validez y carácter vinculante de las normas andinas de derecho secundario o derivado, es decir, aquellas que provienen de órganos comunitarios constituidos, como el Consejo Andino de Ministros de Relaciones Exteriores, La Comisión y la Secretaría General, o para admitir los efectos de las sentencias del tribunal de justicia que les sean aplicables o de las decisiones expedidas por el Parlamento Andino.

No obstante lo anterior, los Estados andinos, a través de la jurisprudencia y de la doctrina, han reconocido las características propias del derecho comunitario al ordenamiento jurídico andino, y se sometieron a la jurisdicción de la Secretaría General de la Comunidad Andina (CAN) y del Tribunal Andino de Justicia.

En todo caso, es de resaltar que la consagración constitucional que admita la validez y carácter vinculante de las normas andinas de derecho secundario o derivado del ordenamiento jurídico andino, permitiría mayor fluidez en la eficacia de las mismas.

4. La Constitución boliviana, a diferencia de las demás cartas políticas andinas, prevé en el artículo 257 la obligatoriedad de que los tratados, protocolos y acuerdos internacionales relacionados con los temas de integración económica estructural y cesiones de competencias institucionales a organismos internacionales o supranacionales, en el marco de procesos de integración, sean objeto de referendo popular.
Lo anterior, sin lugar a equívocos, permite asegurar legitimidad en el proceso de integración andino, aspecto olvidado en el interior de la Comunidad Andina (CAN) y que se configura como una de las causales principales de la crisis del mencionado proceso.

Para el efecto,

[...] no se puede pretender afirmar que la integración por sí sola sea una ideología lo suficientemente fuerte para legitimar los procesos de integración; necesariamente se debe acudir a los actores políticos, a los actores sociales y culturales, para que mediante su participación en los procesos de integración, se adquiera una verdadera legitimidad (Barros, 1989: 68).

Es por lo anterior que "la participación de la ciudadanía en el proceso de integración es un factor de legitimidad y una condición de éxito: si solo participan los gobiernos, el proceso se estanca y fracasa" (Vacchino, 1990: 9).

5. Las constituciones colombiana y ecuatoriana, y en mayor escala la peruana (por no prever nada sobre el particular), no son expresas en cuanto a las posibilidades que tienen los referenciados Estados de ceder competencias. En todo caso, y a pesar de lo anterior, se afirma que mediante la legalización de los tratados, acuerdos y protocolos que conforman el ordenamiento jurídico andino, se puede deducir que sí es viable una delegación de competencias (Sánchez, 2000 y Pérez, 2000).

Todo proceso de integración requiere de la cesión de competencias por parte de los Estados miembros al respectivo correspondiente supranacional. De acuerdo con lo anterior, es pertinente aclarar que en los procesos de integración no existe en sentido técnico traspaso alguno de soberanía, la cual por lo demás, como es atributo esencial del Estado, no es susceptible de división en partes o fracciones. Lo que opera en un proceso de integración es en realidad una transferencia de 
competencias, las que no obstante desprenderse del poder soberano del Estado no conllevan un desmembramiento de la soberanía propiamente dicha.

\begin{abstract}
En otras palabras, la transmisión de facultades que tiene lugar en el marco de un esquema de integración, no ocasiona la partición de la soberanía que continúa como un todo en poder del Estado, en tanto y en cuanto es la Nación quien puede marcar su alcance a través de la redacción que se dé en el tratado constitutivo y en última instancia, advirtiendo que el país miembro puede recuperar las competencias cedidas en el momento que crea oportuno por medio de su retiro del proceso, mediante la respectiva denuncia (Perotti, 2007: 441 y 442).
\end{abstract}

En consecuencia, "la creación de un sistema de integración tiene por efecto producir una reordenación de las funciones fundamentales de los Estados, es decir de la soberanía" (Pescatore, 1974: 15) y ello no conduce a un debilitamiento de los poderes soberanos del Estado, sino un redimensionamiento en el que todos los demás Estados participan en el ejercicio de la soberanía.

La formación de una comunidad o de un esquema de integración bajo un sistema jurídico supranacional no lesiona el concepto de soberanía, ya que cada Estado participante ha limitado voluntariamente los alcances de su poder público a cambio de las ventajas que reciba del proceso, y tiene una potestad intrínseca para organizarse jurídicamente y proyectarse externamente como miembro de la comunidad internacional. En otras palabras,

[...] la integración comunitaria responde y se afianza en la concepción de una soberanía relativa de los Estados, no reconocida como un poder estatal supremo, absoluto e ilimitado, sino como algo menguado y circunscrito por la interacción de los demás actores de la comunidad internacional; lo que implica la reasignación de competencias específicas de los países miembros en organismos comunitarios para hacer viables los procesos de integración (Ponce de León, 2001: 48).
6. Los tratados internacionales que crean los compromisos y las instituciones que garantizan las finalidades propias del proceso de integración andino, jurídicamente no tienen una trascendencia mayor que los mismos tratados en otros campos, por tanto se debe negar que la fuerza vinculante de aquellos sea mayor.

Lo anterior no resulta aplicable en la Unión Europea, pues para su jurisprudencia y doctrina el hecho de que los tratados que versen sobre el desarrollo de espacios regionales integrados y sobre la creación de instituciones jurídicas que regulan la actividad de los Estados y de las personas de cada uno de ellos,

\section{[...] implica una verdadera transforma- ción de esas normas (Díez, 1998), pues ya no hacen parte de una estructura nor- mativa guiada por los principios de bue- na fe y pacta sum servanda, sino que empiezan a ser normas con una fuerza coercitiva real respaldada en institucio- nes legítimamente constituidas, lo que lleva a concluir que los tratados interna- cionales no deben estudiarse bajo un enfoque de derecho internacional, sino bajo una perspectiva comunitaria, que es la acepción propia para este estudio.}

7. No existe, en el interior del derecho andino de la integración, una materialización del principio de jerarquía normativa. Al respecto, es pertinente anotar que en un Estado constitucional de derecho los principios fundamentales del sistema de normas se contemplan en la propia constitución; pues bien, en los tratados, acuerdos y protocolos que conforman el ordenamiento jurídico andino no hay referencia alguna al principio de jerarquía normativa. Es así que la configuración del sistema de normas, y de cada categoría en particular, ha sido obra de la jurisprudencia comunitaria y de la doctrina. Sin duda, tal circunstancia afecta profundamente a un elemento esencial de una comunidad de derecho, como lo es la Comunidad Andina (CAN). Este desolador panorama nos conduce a una situación absolutamente precaria del sis- 
tema de normas comunitario. En este sentido, se hace difícil entender, desde la óptica del derecho constitucional, cómo un sistema de normas puede existir sin reconocerse un principio fundamental de articulación del mismo, como es el principio de jerarquía normativa.

\section{CONCLUSIONES}

1. La creación del espacio regional andino debe tener un fundamento constitucional que faculte a cada uno de los Estados a ceder parte de sus competencias a las instituciones supranacionales creadas por los tratados constitutivos, pues la falta de ese elemento en la cláusula general de competencia pondría en riesgo el funcionamiento normal a futuro de las instituciones regionales, y un conflicto económico y jurídico en el interior de cada uno de los Estados.

2. La efectividad del ordenamiento jurídico andino debe ser liderada, prioritariamente, por los órganos e instituciones que conforman el sistema andino de integración (SAI), de lo contrario, si se deja la referenciada actividad de manera exclusiva a las instituciones internas de los países miembros, se incurriría en la falta de unidad de concepciones y, como consecuencia de ello, en un funcionamiento anormal de la Comunidad Andina (CAN).

3. Es necesario que el derecho andino de la integración se configure como un instrumento al servicio de la población de los países andinos y en el que esté ausente todo carácter político. En otras palabras, es necesario construir un derecho andino de integración despolitizado y técnico.

4. La integración andina implica un proceso jurídico que rompe el principio constitucional clásico de jerarquía normativa, previsto en el interior de las cartas políticas de los países miembros de la Comunidad Andina (CAN).

5. Difícilmente pueden asimilarse los tratados, acuerdos y protocolos que conforman el orde- namiento jurídico andino a las constituciones políticas de los países andinos. Es por lo anterior que, por cuestiones de orden jerárquico, resulta de relevancia que las cartas políticas de los Estados miembros prevean clara y expresamente las bases jurídicas del proceso de integración andino.

\section{REFERENCIAS}

Balaguer, F. (1991). Fuentes del derecho. Madrid, España: Tecnos.

Barros, Ch. (1989, junio-julio). Atribuciones del Parlamento Andino como órgano principal del Acuerdo de Cartagena y orientador del proceso de integración subregional. En revista Integración Latinoamericana. Buenos Aires.

Brewer, A. (2003). Derecho comunitario andino. Lima, Perú: Fondo Editorial de la Pontificia Universidad Católica del Perú. Instituto de Estudios Internacionales.

Caballero, S. y Anzola, G. (1995). Teoría constitucional. Bogotá, Colombia: Temis.

Chofre, S. (2007, enero). El derecho comunitario como derecho premoderno (algunas reflexiones acerca del derecho comunitario). En Revista Nuevos Estudios Jurídicos, (12) 1. Documento extraído el 2 de enero de 2011 de http://vlex.com/ $\mathrm{vid} / 59087399$

De Cabo, C. (2000). El concepto de ley. Madrid, España: Trotta.

Díez, H. (1998). La posición del derecho internacional en el ordenamiento comunitario. En Palomares García, J.R. (2008, mayo). Comunidad Andina: ¿es vinculante el derecho comunitario? En Revista Via Inveniendi et Iudicandi, 5. Madrid, España: Edit. Mc Graw Hill. Documento extraído el 20 de noviembre de 2010 de http://vlex.com/vid/42489356 
Ferrajoli, L. (2003). Pasado y futuro del Estado de derecho. En Carbonell, Miguel. Neoconstitucionalismo. Madrid, España: Trotta.

Martínez, D. (2008). La integración en el nuevo constitucionalismo latinoamericano. En Crisis y Perspectiva Comparada de los Procesos de Integración, Segunda Jornada Cátedra Jean Monnet en Colombia. Bogotá, Colombia: Universidad Externado de Colombia. Edit. Eric Tremolada Álvarez.

Palomares, J. (2008, mayo). Comunidad Andina: ¿es vinculante el derecho comunitario? En Revista Via Inveniendi et Iudicandi, 5. Documento extraído el 20 de noviembre de 2010 de http://vlex.com/ vid/42489356

Pérez, L. (2000). Los principios básicos del derecho comunitario en las constituciones venezolanas de 1961 y 1999. Recuperado el 15/03/07 de www. comunidadandina.org/bda/docs/VE-INT-0008.pdf, en Palomares García J.R. (2008, mayo). Comunidad Andina: ies vinculante el derecho comunitario? En Revista Via Inveniendi et Iudicandi, 5. Documento extraído el 20 de noviembre de 2010 de http://vlex. com/vid/42489356

Perotti, A. (2007). Habilitación constitucional para la integración comunitaria. Buenos Aires, Argentina: Juruá.

Pescatore, P. (1974, marzo). La importancia del derecho en un proceso de integración económica. En Revista Derecho de la Integración 15, (II). Buenos Aires, Argentina: Editorial Intal.

Plata, L. y Donna, C. (2009, junio). La naturaleza jurídica de las normas comunitarias. En Revista de Derecho de la División de Ciencias Jurídicas 31. Documento extraído el 2 de enero de 2011 de http://vlex.com/vid/66329276

Ponce de León, E. (2001). Temas de derecho comunitario ambiental andino. Bogotá, Colombia:
Universidad Externado de Colombia.

Ramírez, A. (2008). Recopilación jurisprudencial de la Corte Constitucional de Colombia sobre tratados de comercio internacional. Bogotá, Colombia: Fundación Konrad Adenauer y Corporación Pensamiento Siglo XXI.

Ravassa, G. (2005). Derecho mercantil internacional: principios y normas, doctrina y ley. En Palomares García, J.R. (2008, mayo). Comunidad Andina: ies vinculante el derecho comunitario? En Revista Via Inveniendi et Iudicandi, 5. Documento extraído el 20 de noviembre de 2010 de http://vlex. com/vid/42489356

Sánchez, S. (2000). La integración y la Constitución Política de Bolivia. Recuperado el 20/03/07 de http://www.comunidadandina.org/bda/docs/ BO-INT-0003.pdf, en Palomares García, J.R. (2008, mayo). Comunidad Andina: ¿es vinculante el derecho comunitario? En Revista Via Inveniendi et Iudicandi, 5. Documento extraído el 20 de noviembre de 2010 de http://vlex.com/vid/42489356

Tangarife, M. (2002). Derecho de la integración andina. Bogotá, Colombia: Baker \& McKencie.

Vacchino, J. (1990). La dimensión parlamentaria de los procesos de integración regional (tomo I). Buenos Aires, Argentina: Depalma Buenos Aires. BID. Instituto para la Integración de América Latina. 